\title{
O BRASIL DE GETÚLIO VARGAS E A FORMAÇÃO DOS BLOCOS, 1930-1942 (SILVA SEITENFUS, Ricardo António - São Paulo, Companhia Editora Nacional, 1985)
}

René E. Gertz *

Ao escreverem em 1982 uma resenha sobre "relaçб̄es internacionais $\mathrm{e}$ política externa brasileira", Gerson Moura e Maria Regina Soares de Lima destacaram que a inserção do Brasil no contexto internacional durante o primeiro período getulista está se transformando em objeto de um número crescente de estudos. ${ }^{1}$ Neste sentido, o extenso trabalho de Ricardo Seitenfus (488 págs.) representa uma contribuiçao importante e oportuna.

$\mathrm{O}$ trabalho se concentra no triângulo constituído pelo Brasil, Estados Unidos e os dois mais importantes países fascistas da Europa (Alemanha e Itália). O texto está dividido em dois "livros"; o primeiro é dedicado ao período que vai de 1930 até a decretação do Estado Novo em 1937 e o segundo, bem mais extenso e substancioso, se detém no período estadonovista até a declaraçao de guerra ao "Eixo" em 1942.

Após um capítulo introdutório sobre o Brasil que emergiu da revolução de 1930, o Autor mostra a importância que passa a ter para o país a Alemanha nazista, a qual se transforma no seu segundo mais importante parceiro comercial. A Itália aparece menos como parceiro comercial, mas sua importância durante o período decorre sobretudo da presença de consideráveis contingentes populacionais de origem italiana no Brasil e das relações entre o fascismo italiano e o integralismo brasileiro (fatores que evidentemente também pesam nas relaçбes germano-brasileiras). A importância da análise das relaçбes Brasil-Estados Unidos nao necessita de grandes justificativas.

Mas a parte mais importante do texto está sem dúvida no segundo "livro". Nesta parte sao estudadas com detalhe as idas e vindas do Brasil dentro do conflito mais geral entre as naçס̃es européias do "Eixo" e os interesses dos Estados Unidos. Por um lado mostra-se muito claramente o interesse americano para manter o Brasil na sua esfera de interesses - preocupaçå muito compreensível a partir da instauração no Brasil de um regime com características comparáveis aos regimes fascistas e pela presença no po- 
der de diversos elementos declaradamente simpáticos aos regimes "fortes". Por outro lado estudam-se minuciosamente as aproximaçбes e as crises no relacionamento do Brasil sobretudo com a Alemanha (mas também com a Itália) e as divergências existentes a este respeito dentro do governo varguista. Extremamente interessante é a descriçao do processo desencadeado em meados de 1940 com as vitórias bélicas alemãs e as manifestaçðes dúbias de Getúlio Vargas a respeito, seguida do estudo das relaçôes com os Estados Unidos a partir daquele instante até a definição clara em favor dos "Aliados".

Toda esta trama e todo este jogo sao descritos de forma fluente com base em fontes muito amplas e importantes: arquivos particulares brasileiros, arquivos diplomáticos da Alemanha, do Brasil, dos Estados Unidos e da Itália, impressos oficiais e semi-oficiais destes países, depoimentos de participantes dos acontecimentos, bibliografia publicada sobre o assunto, trabalhos acadêmicos nao publicados, jornais e revistas.

No que tange às fontes o trabalho se Seitenfus é sem dúvida o estudo mais rico que se publicou até agora sobre a presença do Brasil no cenário internacional no período em apreço. Por isso está destinado a constituir consulta obrigatória de agora em diante para quem quiser estudar este tema específico ou algum dos muitos temas correlatos.

Mas o trabalho também apresenta alguns pequenos problemas para os quais é necessário chamar a atenção, justamente porque ele com certeza se transformará em fonte de referência bastante freqüente. Estes problemas se explicam em grande parte pela história do próprio livro. Foi apresentado originalmente como tese de doutoramento na Universidade de Genebra (1979). Tudo indica que a versão agora publicada é uma tradução literal do original, sem revisão alguma do autor (na própria revisão da tradução há deficiências). Com isto nao foram retiradas do texto várias passagens que só tinham sentido em função do público a que ele se destinava: a banca examinadora que possivelmente, como costuma acontecer nestes casos, desconhecia detalhes corriqueiros para uma pessoa medianamente informada no Brasil. Numa resenha de Paulo Sérgio Pinheiro já foram apontados alguns problemas daí decorrentes. O recensista mostra que o autor faz "julgamentos extremamente lapidares sobre política interna e personagens brasileiros" que na realidade sao muito mais complexos e controversos do que pensa Seitenfus. $^{2}$ As falhas apontadas por P.S. Pinheiro, porém, não comprometem o cerne do trabalho, já que se referem a circunstâncias marginais ao interesse central do livro.

Há no entanto também alguns problemas nas passagens diretamente ligadas ao tema central. Quero mostrar isso à mão de alguns exemplos retirados de partes que abordam o relacionamento germano-brasileiro, mas 
que em muitos casos também se aplicam, mutatis mutandis, a outras partes do livro.

Pode-se iniciar com um aspecto praticamente formal. As relações germano-brasileiras de 1930 a 1938 já foram objeto de uma tese acadêmica na Alemanha, feita por Käte Harms-Baltzer. ${ }^{3}$ Mesmo que o autor ño a arrole na bibliografia, tomou conhecimento desta tese, pois a cita numa nota de rodapé de menor importância, quando discute se o embaixador alemão Ritter era ou ño membro do partido nazista (p.85). Mas nas passagens mais densas em que trata das relaçбes entre Alemanha e Brasil, não há nenhuma referência ao trabalho da autora.

Parece fora de dúvida que as ciências sociais se constroem em grande parte através do confronto recíproco com a produção da comunidade cientifica. No caso, Harms-Baltzer utilizou em grande parte as mesmas fontes que Seitenfus e teria sido sem dúvida muito importante se este tivesse partido do trabalho já realizado pela autora, para mostrar suas eventuais deficiências, a fim de deixar claro em que consiste o avanço ou a contribuição de sua abordagem. Em função do mutismo em relação ao trabalho já existente, ficamos sem saber se os dois pesquisadores nao esmiuçaram o mesmo tema sob uma mesma perspectiva e chegaram às mesmas conclusões - o que constituiria um evidente desperdício de energia. De qualquer modo, neste ponto o autor não cumpriu sua promessa de que seu "método baseia-se essencialmente na crítica e na confrontação das fontes de origens diversas" (p.XX). Problemas semelhantes poderiam ser apontados em relação ao tratamento dado à bibliografia já existente sobre os temas tratados em outros capitulos.

Um outro ponto dentro deste contexto: o Autorinsiste em que a Alemanha (como também a Itália) exercia, além da diplomacia oficial em relação ao Brasil, uma ação paralela, que consistia na atividade do partido nazista, na difusao de idéias racistas e nazistas através de escolas e de outras instituições culturais e recreativas, além de outras atividades subversivas semelhantes. Sem dúvida tudo isto é verdade. Mas constitui uma clara afronta às evidências públicas e notórias afirmar que "as autoridades governamentais brasilieiras, em especial federais, não estão a par das atividades nazistas durante os anos 1933-1937" (p.94).

Mas independente disto, ao abordar a atividade da subversao paralela no contexto da morte, em 1938, de Frederico Kopp, secretário geral da $\mathrm{Fe}$ deração 25 de Julho, o Autor cita|um relatório do embaixador alemao em que este diz que "embora (a Federação) tenha um caráter apolítico, Kopp naturalmente manteve estreitas relaçðes com nacionais alemães, e também com a embaixada e o partido (pp.209-210). O grifo é de Seitenfus. Na verdade a frase nao revela nada de extraordinário. Seria motivo de espanto - 
e justificaria o grifo - se o embaixador afirmasse que o secretário geral de uma instituição que se propðe oficialmente a incrementar as relaçбes germano-brasileiras no campo cultural e científico nunca tivesse mantido qualquer contato com a embaixada alemã nem com os representantes oficiais e sabidos do único partido deste país. Mais: Seitenfus atribui à Federação uma importância que ela nao teve e é por isso que nao encontrou "qualquer traço" de documentos sobre o caso Kopp nos arquivos diplomáticos brasileiros (p.213). Instituições importantes neste caso da subversão paralela são, em contrapartida, o Deutsches Auslandsinstitut (DAI) e o Volksbund für das Deutschtum im Ausland (VDA) - e a respeito destas instituições e seu apoio a atividades no Brasil o Autor teria encontrado bastante material no Arquivo Nacional de Koblenz (uma fonte citada e utilizada por Harms-Baltzer).

Além dos pontos indicados há ainda diversos outros "cochilos" maiores e menores no capítulo em que estou concentrando minha exemplificaçao. Quero citar apenas alguns: ao falar do sistema de quotas para imigrantes, ficamos sabendo que "esse sistema tende a favorecer os países de imigração recente, como o Japão..., em detrimento daqueles... como a Alemanha" (p.180). Conheço diversos autores de respeito que afirmam justamente o inverso. Mais uma vez a ausência de uma confrontação com a bibliografia já existente não permite saber se estamos diante de uma afirmação mal pensada ou diante de uma revisão bem fundada.

A abordagem das relaçøes entre integralismo e nazismo também sofre tropeços em algumas passagens. Ao contrário de outros autores, Seitenfus reconhece corretamente o relacionamento complexo e problemático entre ambos (pp.55 e 100), por exemplo), mas sua indefinição ou suas idéias préconcebidas aparecem, quando trata da questão da participação nazista na intentona integralista de 1938. Numa nota de rodapé (p.201) cita uma declaração do chefe nazista no Brasil, von Cossel, feita ao historiador alemão Hans-Adolf Jacobsen: "Vargas sabia muito bem que nós, alemãs, nada tínhamos a ver com o golpe integralista". Comentário de Seitenfus: "A verificação de diversos indícios\nos permite duvidar destas declaraçס̃es e arrependimentos". Na mesma página é citado um relatório do embaixador alemao Ritter sobre o mesmo assunto: "Se alguma coisa de tangível (sobre a participação alemã na intentona - REG) tivesse sido descoberta..., o governo certamente se teria apressado a publicá-la e a teria utilizado contra nós". Comentário de Seitenfus: "Ritter vê com clareza, pois o Brasil tem apenas indicaçఠes sobre uma eventual participaçđo alemã ". Nao pretendo entrar na discussão deste assunto efetivamente complexo, mas as citaçбes mostram que o.Autor não está totalmente seguro do que afirma, pois há uma evidente contradição entre os dois comentários. 
A mesma insegurança em relaçđo ao mesmo assunto aparece em outros lugares: ao comentar, numa longa nota de rodapé, o livro de Hunsche sobre o integralismo, ${ }^{4}$ afirma que "o mais ridículo na obra de Hunsche é que ele contradiz a doutrina integralista..." (p.181). Para quem conhece o relacionamento problemático do integralismo com o germanismo e o nazismo, as posiçães do germanista Hunsche sđo totalmente previsíveis e coerentes.

Naturalmente a "depuração" de uma tese escrita para um público estrangeiro nem sempre é fácil e dificilmente se consegue eliminar todos os resquícios. Talvez por isso a publicaçđo de versðes originais nao seja coisa rara no Brasil. Mas o resultado, em geral, é o comprometimento da qualidade. Felizmente a tese de Seitenfus tem tantas qualidades que as deficiências sao plenamente compensadas. Mas sem dúvida estaremos diante de uma obra que merecerá muito mais elogios, se o autor fizer para a 2 a ediçao, que não deverá tardar, uma reformulação do trabalho, depois que ele agora já passou por um considerável, e nestes casos em geral muito benéfico, período de "decantação".

\section{NOTAS}

1 - Moura, Gerson e Lima, Maria Regina Soares de. "Relaçð̃es internacionais e política externa brasileira: uma resenha bibliográfica". In: Boletim Informativo e Bibliográfico de Ciências Sociais/ANPOCS, 13/1982, p.8.

2 - Folha de Säo Paulo, 24.11.1985.

3 - Harms-Baltzer, Käte. Die Nationalisierung der deustschen Einwanderer und ihrer Nachkommen in Brasilien als Problem der deutschbrasilianischen Beziehungen; 1930-1938. Berlim, Colloquium Verlag, 1970.

4 - Hunsche, Karl-Heinrich. Der brasilianische Integralismus. Stuttgart, Verlag von W. Kohlhammer, 1938.

* Professor no Departamento de História da PUCRS. 